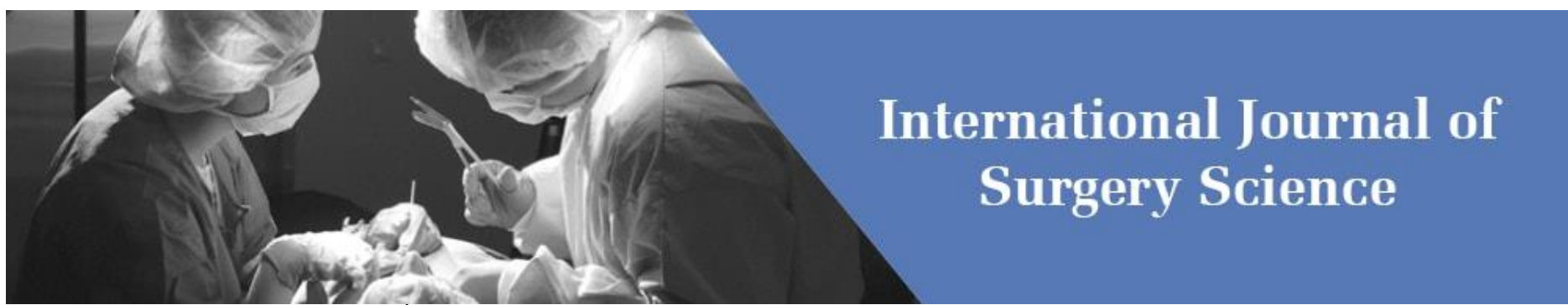

E-ISSN: 2616-3470

P-ISSN: 2616-3462

(C) Surgery Science

www.surgeryscience.com

$2020 ; 4(2): 636-640$

Received: 27-02-2020

Accepted: 28-03-2020

Dr. Matlapudi Sanjeeva Rao

Associate Professor, Department of

General Surgery, Konaseema

Institute of Medical Science,

Amalapuram, Andhra Pradesh,

India

Dr. Gnana Bhushan Kumar

Associate Professor, Department of

General Surgery, Konaseema

Institute of Medical Science,

Amalapuram, Andhra Pradesh. India

\section{Prospective study of clinicoepidemiology, presentation and treatment outcome of lower extremity peripheral artery disease (LE-PAD)}

\author{
Dr. Matlapudi Sanjeeva Rao and Dr. Gnana Bhushan Kumar
}

DOI: https://doi.org/10.33545/surgery.2020.v4.i2g.458

\section{Abstract}

Background: Peripheral arterial disease is one among three major cardiovascular diseases and is an important contributor of death and disabilities in low and middle income countries. Symptoms of peripheral arterial disease depend upon the severity of narrowing of artery. Based on severity of disease there are various modalities of treatment is available to prevent the progress of disease and save the limb.

Method: This is a prospective, observational, cross sectional study conducted in the department of general surgery. Detailed chronological clinical history is taken, after that patient was evaluated clinically for vascular abnormalities of lower extremities. All patients were followed for minimum 6 month for the evaluation of course of disease and at each visit detail examination was repeated.

Result: Dorsalis pedis artery was more commonly involved in thromboangitis obliterans patients then peripheral artery disease (37.5\% vs $4.34 \%$ ). Regarding mode of treatment all patients in both group received medical treatment and life style modification. Lumber sympathectomy was done in $4(8.6 \%)$ patients in PAD group and 1(6.25\%) in TAO group. Amputation of leg was done in 18(39.10\%) in PAD group.

Discussion and Conclusion: Diabetes and hypertension was common comorbid condition associated with PAD. Most of the patients have habit of tobacco use. Gangrene and ulcer are common presentation of patients and most of the patients required amputation and disarticulation. Some symptoms improved by life style modification and medical management. The mean duration of stay in hospital was longer in PAD patients then TAO patients.

Keywords: Peripheral artery disease, thromboangitis obliterans, treatment outcome, presentation

\section{Introduction}

Peripheral arterial disease is one among three major cardiovascular diseases and is an important contributor of death and disabilities in low and middle income countries. As per Global Burden of Disease of 2017, the world wide number of incident cases was 10.8 million and most of them were asymptomatic ${ }^{[1,2]}$. It is debilitating atherosclerotic occlusion of arteries in the lower extremities present as intermittent claudication, atypical leg pain, critical limb ischemia and occasionally acute limb ischemia depending upon the severity of diseases ${ }^{[3]}$. It is the manifestation of atherosclerosis of the arteries of leg and management of atherosclerosis is important concern in medical management of lower extremity peripheral artery disease. Various non atherosclerotic conditions like thromboangitis obliterans (TAO), arterial fibro dysplasia, takayasu arteritis and emboli can also cause symptoms like intermittent claudication. Risk to involve limb is greater in TAO then in other arteriosclerosis diseases. Symptoms of peripheral arterial disease depend upon the severity of narrowing of artery. Based on severity of disease there are various modalities of treatment is available to prevent the progress of disease and save the limb. Management of patient with chronic limb ischemia is complex, it include medical management, surgical management and combination of both. In addition to risk factor modification medical therapy includes antiplatelet agents like aspirin and clopidogrel, vasodilators like calcium channel blocker, neftidofuryl, cilastazol and pentoxyfylline, exercise rehabilitation, surgical therapy like endovascular interventions, or surgical bypass ${ }^{[4,5]}$. Various studies have been conducted to evaluate treatment outcome, Gardner AW, Afaq A et al. have concluded that conservative and medical management is effective for patient with asymptomatic PAD and patients with intermittent claudication but

\section{Dr. Gnana Bhushan Kumar}

Associate Professor, Department of

General Surgery, Konaseema

Institute of Medical Science,

Amalapuram, Andhra Pradesh,

India 
patient with severe PAD typically require revascularization of the lower extremities ${ }^{[4]}$. Firnhaber JM, Powell CS et al. has concluded that Surgical revascularization should be reserved for patients with severe claudication who have an inadequate response to medical therapy ${ }^{[6]}$. Based on previous studies present study is designed to evaluate the clinicoepidemiology and presentation of lower extremity peripheral artery disease (LE-PAD) in our patient. To study the mode of treatment and its outcome in various patient with LA PAD admitted in our hospital.

\section{Material and Method}

This is a prospective, observational, cross sectional study conducted in the department of general surgery Konaseema institute of medical science Amalapuram Andhra Pradesh from January 2017 to April 2020.

Selection of patient:-

Patients with clinical feature of lower extremity peripheral artery disease were selected for this study based on following inclusion and exclusion criteria.

Table: Exclusion and inclusion criteria

\begin{tabular}{|c|c|}
\hline Inclusion criteria & Exclusion criteria \\
\hline Both sex & History of trauma \\
\hline All ages & Involving other region of body \\
\hline $\begin{array}{c}\text { Patient with feature of lower extremity } \\
\text { peripheral artery disease like intermittent } \\
\text { claudication, rest pain gangrene }\end{array}$ & $\begin{array}{c}\text { Pain of lower extremities } \\
\text { neurological in nature }\end{array}$ \\
\hline Evidence based on Doppler study & \\
\hline
\end{tabular}

Sample size: - Based on exclusion and inclusion criteria sixty two patients with clinical feature of lower extremity peripheral artery disease were enrolled for this study.

Ethics: Present study is approved by institutional ethics committee. A written informed consent was obtained from all patients before enrolling them for study.

\section{Method}

Once patient has been admitted in general surgery department detailed chronological clinical history is taken, after that patient was evaluated clinically for vascular abnormalities of lower extremities. Extent of disease severity was evaluated by assessment of vascular insufficiency, distribution and type of pain, extent of colour change, gangrene and absence of peripheral pulses. All essential laboratory investigation was done for atherosclerosis and patients were further evaluated for level and degree of obstruction by Doppler scanning. As per the severity of disease treatment of patient was individualised with an aim to save the limb. All patients were followed for minimum 6 month for the evaluation of course of disease and at each visit detail examination was repeated. For maintenance of record a predesigned structured Performa was used every patient.

Statistical analysis: - Data was collected on Microsoft excel sheet and analysis was done by using mean and proportion.

\section{Result}

In present study of two years and 10 month duration 62 patients were enrolled as per selection criteria.

Table 2: Clinicoepidemiology of patients

\begin{tabular}{|c|c|c|c|c|}
\hline \multicolumn{3}{|c|}{ variables } & PAD (peripheral artery disease) & TAO (thromboangitis obliterans) \\
\hline \multicolumn{3}{|c|}{ Number of patients } & 46 & 16 \\
\hline \multicolumn{3}{|c|}{ Age in years(Mean \pm SD) } & $64.30 \pm 10.90$ & $47.06+11.94$ \\
\hline \multicolumn{3}{|c|}{$\operatorname{Sex}(\mathrm{M} / \mathrm{F})$} & $30 / 16$ & $14 / 2$ \\
\hline \multirow{4}{*}{ Associated co-morbid conditions } & \multicolumn{2}{|c|}{ Diabetes } & $22(47.82 \%)$ & $4(25 \%)$ \\
\hline & \multicolumn{2}{|c|}{ Hypertension } & $16(34.78)$ & $2(12.5 \%)$ \\
\hline & \multicolumn{2}{|c|}{ Renal disorder } & $3(6.52 \%)$ & $1(6.25 \%)$ \\
\hline & \multicolumn{2}{|c|}{ Hepatic disorder } & $1(2.17 \%)$ & 0 \\
\hline \multirow{2}{*}{\multicolumn{3}{|c|}{$\begin{array}{c}\text { Smoking (past) } \\
\text { Smoking (present) }\end{array}$}} & $24(52.17 \%)$ & $14(87.5 \%)$ \\
\hline & & & $14(30.435 \%)$ & $12(75 \%)$ \\
\hline \multirow{4}{*}{ Habits } & \multirow{2}{*}{ Type of smocking } & Cigarette & $16(34.78 \%)$ & $6(37.5 \%)$ \\
\hline & & Traditional & $8(17.39 \%)$ & $8(50 \%)$ \\
\hline & \multicolumn{2}{|c|}{ Tobacco chewing } & $12(26.08 \%)$ & $10(62.5 \%)$ \\
\hline & \multicolumn{2}{|c|}{ alcoholic } & $14(30.34 \%)$ & $6(37.5 \%)$ \\
\hline
\end{tabular}

As per table 2 out of 62 patient lower extremity peripheral artery disease (LE-PAD) 46 patients have peripheral artery disease and 16 have TAO (thromboangitis obliterans). The mean age of patient in PAD group was $64.30 \pm 10.90$ years and in TAO (thromboangitis obliterans) group was $47.06+11.94$ years. In PAD group 30 were male and 16 were female in TAO group 14 were male and 2 were female. Out of 46 patients, 22(47.82\%) have diabetes in PAD group and $4(25 \%)$ patients in TAO group have diabetes. Regarding associated comorbid conditions diabetes was present in $22(47.82 \%)$ patients in PAD and $4(25 \%)$ in TAO patients. Hypertension was present in $16(34.78 \%)$ patients in PAD and $2(12.5 \%)$ in TAO patients. Renal disorder was present in $3(6.52 \%)$ patients in PAD and $1(6.25 \%)$ in TAO patients. Hepatic disorder was present in
$1(2.17 \%)$ patients in PAD and absent in TAO patients. Past history of smocking was present in $24(52.17 \%)$ patients in $\mathrm{PAD}$ and $14(87.5 \%)$ patients in TAO group. In PAD patients $14(30.435 \%)$ patients were smoker at time of enrolment and in TAO group $12(75 \%)$ patients were smoker at time of enrolment. Regarding type of smocking practice $16(34.78 \%$ ) use to have cigarette and $6(37.5 \%)$ used to have traditional smocking method in PAD group. In TAO group 6(37.5\%) have habit of cigarette smoking and $8(50 \%)$ patients have habit of traditional way of smocking. Tobacco chewing was present in $12(26.08 \%)$ patients in PAD and $10(62.5 \%)$ in TAO patients. In PAD group $14(30.34 \%)$ patients were alcoholic and in TAO group $6(37.5 \%)$ patients were alcoholic. 


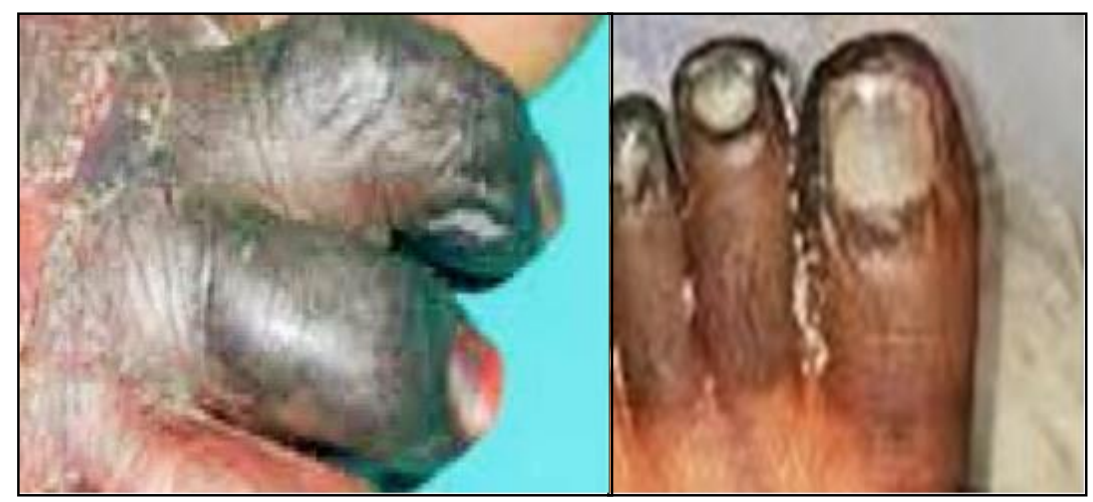

Fig 1: Gangrene of finger and toe in lower extremities peripheral artery disease

Table 3: Clinical presentation and extent of involvement of limb

\begin{tabular}{|c|c|c|}
\hline Variables & $\begin{array}{c}\text { PAD(peripheral } \\
\text { artery disease) }\end{array}$ & $\begin{array}{c}\text { TAO (thromboangitis } \\
\text { obliterans) }\end{array}$ \\
\hline Atypical pain syndrome & $1(2.17 \%)$ & $1(6.25 \%)$ \\
\hline Claudication(ICl) & $4(8.6 \%)$ & $1(6.25 \%)$ \\
\hline Rest pain(RP) & $4(8.6 \%)$ & $2(12.5 \%)$ \\
\hline ICl +RP & $2(4.34 \%)$ & $2(12.5 \%)$ \\
\hline ICl +RP+ Gangrene & $23(50 \%)$ & $8(50 \%)$ \\
\hline ICl +RP + ulcer & $12(26.08 \%)$ & $2(12.5 \%)$ \\
\hline Gangrene of toe & $6(13.04 \%)$ & $6(37.5 \%)$ \\
\hline Gangrene of foot & $8(17.39 \%)$ & $2(12.5 \%)$ \\
\hline Gangrene of foot and leg & $6(13.04 \%)$ & 0 \\
\hline Gangrene above knee & $3(6.52 \%)$ & 0 \\
\hline
\end{tabular}

As per table 3 atypical pain syndromes was clinical presentation in $1(2.17 \%)$ patient in PAD group and $1(6.25 \%)$ patients in TAO group. Claudication was clinical presentation in $4(8.6 \%)$ patients in PAD group and 1(6.25\%) patients TAO group. Rest pain was clinical presentation in $4(8.6 \%)$ patients in PAD group and $2(12.5 \%)$ patients TAO group. Claudication and rest pain both was clinical presentation in $2(4.34 \%)$ patients in PAD group and $2(12.5 \%)$ patients in TAO group. In PAD group $23(50 \%)$ patients were presented with gangrene and $8(50 \%)$ patients in TAO group presented with gangrene. Ulcer was presented in
$12(26.08 \%)$ patients in peripheral artery disease group and $2(12.5 \%)$ patients in thromboangitis obliterans group.

Regarding site of gangrene $6(13.04 \%)$ patients in PAD group has gangrene in toe, $8(17.39 \%)$ have gangrene in foot, $6(13.04 \%)$ have gangrene in foot and leg and $3(6.52 \%)$ have gangrene above knee. Similarly in TAO patients $8(50 \%)$ have gangrene in toe and $2(12.5 \%)$ have gangrene in foot.

Table 4: Site of involvement of arteries in lower extremities

\begin{tabular}{|c|c|c|}
\hline Site of involvement & $\begin{array}{c}\text { PAD(peripheral } \\
\text { artery disease) }\end{array}$ & $\begin{array}{c}\text { TAO (thromboangitis } \\
\text { obliterans) }\end{array}$ \\
\hline Dorsalis pedis artery & $2(4.34 \%)$ & $6(37.5 \%)$ \\
\hline Infra poplitial artery & $8(17.39 \%)$ & $10(62.5 \%)$ \\
\hline Poplitial artery & $28(60.86 \%)$ & 0 \\
\hline Femoral artery & $8(17.39 \%)$ & 0 \\
\hline
\end{tabular}

Dorsalis pedis artery was more commonly involved in thromboangitis obliterans patients then peripheral artery disease $(37.5 \%$ vs $4.34 \%)$. Infra poplitial artery was also more commonly involved in thromboangitis obliterans patients then peripheral artery disease (62.5\% vs $17.39 \%)$. Poplitial artery was involved in $28(60.86 \%$ ) patients in PAD group and absent in TAO patients. femoral artery was involved in $8(17.39 \%)$ patients in PAD group and absent in TAO patients.

Table 5: Treatment modalities and outcome of treatment

\begin{tabular}{|c|c|c|}
\hline Variables & PAD(peripheral artery disease) & TAO (thromboangitis obliterans) \\
\hline Medical treatment and life style modification & 46 & 16 \\
\hline Lumber sympathectomy & $4(8.6 \%)$ & $1(6.25 \%)$ \\
\hline Amputation & $18(39.10 \%)$ & 0 \\
\hline Disarticulation & $8(17.40 \%)$ & 0 \\
\hline \multicolumn{3}{|c|}{ Outcome of medical management } \\
\hline Symptoms & relieved & Not relieved \\
\hline Atypical pain syndrome & 1 & 1 \\
\hline Claudication(ICl) & 6 & 2 \\
\hline Healing of ulcer & 3 & 3 \\
\hline \multicolumn{3}{|c|}{ Outcome of lumber sympathectomy } \\
\hline Atypical pain syndrome & 1 & 1 \\
\hline Claudication $(\mathrm{ICl})$ & 3 & 1 \\
\hline Healing of ulcer & 3 & 1 \\
\hline \multicolumn{3}{|c|}{ Outcome of operative procedure } \\
\hline Variables & PAD(peripheral artery disease) & TAO (thromboangitis obliterans) \\
\hline Uneventful & 12 & 0 \\
\hline Infection & 2 & 0 \\
\hline Secondary suturing & 1 & 0 \\
\hline Duration of stay in hospital(days) & $10.43 \pm 7.9$ & $6.35 \pm 2.8$ \\
\hline
\end{tabular}

Regarding mode of treatment all patients in both group received medical treatment and life style modification. Lumber sympathectomy was done in $4(8.6 \%)$ patients in $\mathrm{PAD}$ group and
$1(6.25 \%)$ in TAO group. Amputation of leg was done in $18(39.10 \%)$ in PAD group but in TAO group no patient required amputation. Disarticulation was done in $8(17.40 \%)$ patients in 
TAO group.

Regarding outcome of medical management atypical pain was relieved in one patient, claudication was relieved in 6 patients and ulcer was healed in 3 patients. After lumber sympathectomy atypical pain was relieved in one patient, claudication was relieved in 3 patients and ulcer was healed in 3 patients. Regarding outcome of operative procedure in 12 patients it was not associated with any complication, two patients developed infection and duration of hospitalisation delayed and in one patients secondary suturing was done.

Duration of stay in hospital was $10.43 \pm 7.9$ days in PAD group and $6.35 \pm 2.8$ days in TAO group.

\section{Discussion}

In present observational study sixty two patients with lower extremities peripheral artery disease were evaluated for clinicoepidemiology, presentation and treatment outcome. Mean age of patients with PAD was $64.30 \pm 10.90$ years and TAO was $47.06 \pm 11.94$ years, there was male predominance in both group. Which is supported by the work of Edward J.Boyko,Jessie H.Ahroni,DeniseDavignon ${ }^{1}$ et al. and Shammas NW et al. ${ }^{[7,8]}$ Diabetes and hypertension was common comorbid condition for peripheral artery diseases. Most of the patients in TAO group and many patients in $\mathrm{PAD}$ group were smoker. Traditional way of smocking and tobacco chewing was common in TAO patients. This finding corroborates with finding of Bailey MA,

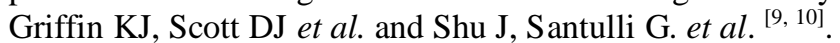

Most of the patients with PAD were presented with gangrene $(50 \%)$ and ulcer as our centre is tertiary care centre. Atypical pain syndrome, intermittent claudication, rest pain and combination of theses was less common clinical presentation. This finding is supported by the work of Shu J, Santulli G.et al. and Lyden SP, Joseph D et al. ${ }^{[11,12]}$ ROSE GA and Mary McGrae McDermott et al. has concluded that most of the patient of $\mathrm{PAD}$ are not presenting with intermittent claudication, this statement corroborate with our finding. ${ }^{13,14}$ dorsal pedis artery and infra poplitial artery are commonly involved in TAO and poplitial and femoral was commonly involved in PAD. Sasaki S, Sakuma M, Kunihara T, Yasuda K et al. has reported that tibial artery is commonly involved in TAO which support our finding ${ }^{[15]}$. Chen, Q., Shi, Y., Wang, Y., \& Li, X et al. has concluded from his study that Peripheral arterial disease involves the arteries distal to the aortic bifurcation in a nonuniform manner which support our study ${ }^{[16]}$. Most of the patients with gangrene or non healing ulcer required amputation or disarticulation. Patients with TAO responded better to medical and life style modification management. After medical management intermittent claudication was relieved better then rest pain. After lumber sympathectomy ulcer healed and claudication get relieved in few patients. This is supported by study of Gardner AW, Afaq A et al., and ) Dormandy JA, Rutherford RB et al. ${ }^{[4,}$ 17] The mean duration of stay in hospital was longer in $P A D$ patients then TAO patients that is $(10.43 \pm 7.9$ days vs $6.35 \pm 2.8$ days). Todd R.VogelMD, MPH et al. has reported that duration of stay in hospital in most of the patients in his study was more than 7 days which support our study. ${ }^{18}$

\section{Conclusion}

From present study we can conclude that TAO was more common in younger age than PAD. There was male predominance in patients with lower extremity peripheral artery disease (LE-PAD). Diabetes and hypertension was common comorbid condition associated with PAD. Most of the patients have habit of tobacco use. Gangrene and ulcer are common presentation of patients and most of the patients required amputation and disarticulation. Some symptoms improved by life style modification and medical management. The mean duration of stay in hospital was longer in PAD patients then TAO patients.

\section{References}

1. Andre Pascal Kengne, Justin Basile EchouffoTcheugui,Differential burden of peripheral artery disease, www.thelancet.com/lancetgh Vol 7 August, 2019.

2. SL James, D Abate, KH Abate, SM Abay, C Abbafati GBD. Disease and Injury Prevalence Global, regional, and national incidence, prevalence, and years lived with disability for 354 diseases and injuries for 195 countries and territories, 1990-2017: a systematic analysis for the Global Burden of Disease Study 2017.Lancet. 2018; 392:17891858.

3. Peige Song, Diana Rudan, Yajie Zhu, Freya JI Fowkes, Kazem Rahimi, F Gerald R Fowkes et al. Global, regional, and national prevalence and risk factors for peripheral artery disease in 2015: an updated systematic review and analysis, www.thelancet.com/lancetgh Vol 7 August, 2019.

4. Gardner AW, Afaq A. Management of lower extremity peripheral arterial disease. J Cardiopulm Rehabil Prev. 2008 ;

28(6):349-357. doi:10.1097/HCR.0b013e31818c3b96.I

5. Francisco J, Serrano Hernando ${ }^{\mathrm{a}}$, Antonio Martín Conejero ${ }^{\mathrm{a}}$. Peripheral Artery Disease: Pathophysiology, Diagnosis and Treatment. Rev Esp Cardiol. 2007; 60(9):969-82.

6. Firnhaber JM, Powell CS. Lower Extremity Peripheral Artery Disease: Diagnosis and Treatment [published correction appears in Am Fam Physician. 2019 Jul 15; 100(2):74]. Am Fam Physician. 2019; 99(6):362-369.

7. Edward J. Boyko ${ }^{12}$ Jessie H. Ahroni ${ }^{1}$ Denise Davignon ${ }^{1}$ Victoria Stensel ${ }^{1}$ Ronald L. Prigeon ${ }^{12}$ Douglas G. Smith ${ }^{34}$ Diagnostic utility of the history and physical examination for peripheral vascular disease among patients with diabetes mellitus, Journal of Clinical Epidemiology. 1997; 50(6):659-668.

8. Shammas NW. Epidemiology, classification, and modifiable risk factors of peripheral arterial disease. Vasc Health Risk Manag. 2007; 3(2):229-234. doi:10.2147/vhrm.2007.3.2.229.

9. Bailey MA, Griffin KJ, Scott DJ. Clinical assessment of patients with peripheral arterial disease. Semin Intervent Radiol. 2014; 31(4):292-299. doi:10.1055/s-0034-1393964

10. Vijayakumar A, Tiwari R, Kumar Prabhuswamy V. Thromboangiitis Obliterans (Buerger's Disease)-Current Practices. Int J Inflam. 2013; 2013:156905. doi: $10.1155 / 2013 / 156905$

11. Shu J, Santulli G. Update on peripheral artery disease: Epidemiology and evidence-based facts. Atherosclerosis. 2018; 275:379-381. doi:10.1016/j.atherosclerosis.2018.05.033

12. Lyden SP, Joseph D. The clinical presentation of peripheral arterial disease and guidance for early recognition. Cleve Clin J Med. 2006; 73(4):S15-S21. doi:10.3949/ccjm.73.suppl_4.s15.

13. Rose GA. The diagnosis of ischaemic heart pain and intermittent claudication in field surveys. Bull World Health Organ. 1962; 27:645-658.

14. Mary McGrae McDermott, Lower Extremity Manifestations of Peripheral Artery Disease, Circulation Research. 2015; 116:1540-1550. 
15. Sasaki S, Sakuma M, Kunihara T, Yasuda K. Distribution of arterial involvement in thromboangiitis obliterans (Buerger's disease): results of a study conducted by the Intractable Vasculitis Syndromes Research Group in Japan. Surg Today. 2000; 30(7):600-605. doi:10.1007/s005950070099.

16. Chen Q, Shi Y, Wang Y, Li X. Patterns of Disease Distribution of Lower Extremity Peripheral Arterial Disease. Angiology. 2015; 66(3). 211218. https://doi.org/10.1177/0003319714525831.

17. Dormandy JA, Rutherford RB. Management of peripheral arterial disease (PAD). TASC Working Group. TransAtlantic Inter-Society Consensus (TASC) J Vasc Surg. 2000; 31(1-2):S1-S296.

18. Todd R. Vogel MD MPH ${ }^{\mathrm{a}}$. Risk factors for readmission after lower extremity procedures for peripheral artery disease Journal of Vascular Surgery. 2013; 58(1):90-97.e4 